\title{
APPLIED BEHAVIORAL ANALYSIS THERAPY IN SPECIAL EDUCATION PRACTICE
}

\author{
Alica Vančová ${ }^{1}$, Kristína Nagyová $^{2}$
}

\begin{abstract}
Applied behavioral analysis (ABA) is an appropriate and scientifically based approach for individuals with different types of handicap. This paper focuses on the brief characteristics of the applied behavioral analysis and also presents the varied use of applied behavioral analysis in special pedagogy. Describing the individually developed ABA educational plans for a participant with autism, the authors point to the effectiveness of intervention based on applied behavioral analysis. For the collection of research data case studies, applied behavioral analysis methods, and participatory observations were used. The obtained data was processed by qualitative analysis. The results confirm the positive results obtained through ABA intervention, especially in the field of communication and behaviour.
\end{abstract}

UDC Classification: 376, DOI: 10.12955/cbup.v7.1438

Keywords: Applied behavioural analysis, stimulation, motivation, prompting, child autism, autism spectrum disorder.

\section{Introduction}

The use of applied behavioral analysis (ABA) is very wide and can be used in different ways and in different areas, in pedagogy and the education of intact child, but also in special pedagogy and the education of children with disabilities. We note that this is not just "autistic therapy", as many internet portals misrepresent. It is a science through which we can change the behavior of adults in different businesses or work with people who are troubled by addictions. It is also useful for problematic behavior of offenders and criminals, as well as gerontopedagogics or special gerontopedagogics in the care of seniors.

Potential achievements are due to the positive changes in behavior preceded by a functional behavior analysis. Therefore, we will focus on defining behavior, analyzing it and concluding on problem and verbal behavior, as they are part of almost every ABA educational program for children with special needs and may be one of the effective intervention options in special education.

\section{Behaviour}

Behavior is a term that we use very often in routine situations without thinking more about what it involves. For ABA, this concept is crucial because the changes that we want to achieve by intervention depend on the correct definition of behavior. Behavior is all that a person does, says how he manifests himself, including what he thinks. In describing the behavior in the ABA, the dead man's rule is very often mentioned, saying that behavior is all he can't do. Behavior must be measurable and cannot include mentalistic concepts (Aue-VanDenBerg, 2009; Simplesteps 2017).

Example 1: A teacher claims that Adam is aggressive at school.

Example 2: A teacher says Adam has struck a classmate 9 times a day at school.

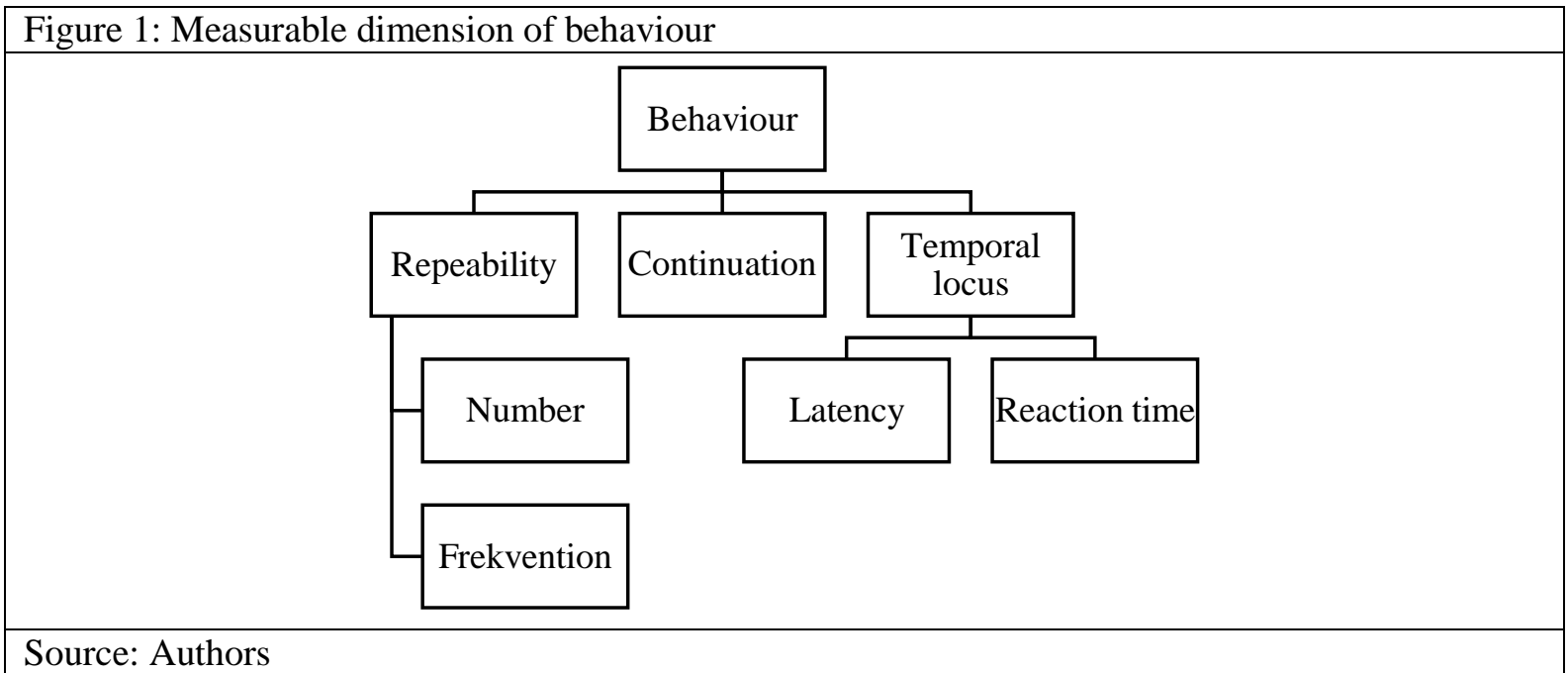

\footnotetext{
${ }^{1}$ Faculty of Education, Comenius University in Bratislava, vancova@fedu.uniba.sk

${ }^{2}$ Faculty of Education, Comenius University in Bratislava, nagyova.kristina25@gmail.com
} 
Which of our cases describes behavior? The first example makes Adam someone, who is aggressive. Under aggressivity, everyone imagines something different. If a teacher wants to measure aggression at school, it could be, for example, a blow. At home, maybe the mum measures screaming or throwing things onto the ground. The measurement would have no significance for us because the data would have very different values. The second case talks about behavior. It is a behavior that can be worked on and modified. If we define behavior in this way, we can say whether the intervention is successful and how it has been reduced. Without a precise definition and measurement of behavior, we cannot say in ABA that behavior has improved. For such a claim, we need to have data to confirm the improvement.

Behavior has several dimensions that we focus on. According to Cooper (2007), we have drawn up a scheme that contains the dimensions (Figure 1).

Knowing this concept is essential in modifying behavior and therefore, in accordance with Cooper et al. (2007) and Gilmore (2015) we characterize them in this section.

Duration is the time we measure from when behavior occurs until it ends. Repetition includes the number of responses or behaviors during observation or the frequency of occurrence of the behaviors over a period of time. The temporal locus, that is, the time at which behavior occurred, describes latency and inter-reaction time. Latency is the time that runs from the time the presentation of the stimulus to the beginning of the response. Intermediate time is the length of time interval between two consecutive behaviors, responses. Usually, one procedure or a combination of several of the following procedures is used to measure behavior:

- Event recording is the marking of the number of behaviors in a digital or mechanical manner, it is not appropriate to use it with too high a frequency of behavior.

- Timing is a procedure that is used to measure duration, latency, or inter-time - can be expressed as a percentage.

- Sampling Time sampling is a measurement that does not provide the exact number of behaviors, but indicates whether or not a behavior occurred in a particular time unit.

In order to be able to modify the behavior, we must analyze the behavior in addition to the measurement and determine its function, so why do people do what they do. Zeissig (2012) and McClleland (2016) mention four following behaviors. Attention - person does everything to get the attention of the surroundings. Negative attention, such as screaming and alerting the child, is also a concern, and is likely to increase future behavior. Leakage - the child will use the behavior so that they do not have to meet the spoken request. If the request is revoked, the behavior is repeated. Tactile item - the child wants to get a tangible item, such as a sweet at the shop, where it starts crying if parent doesn't allow it. Sensory stimulation - the child gains an automatic boost that forces him/her to repeat the behavior, as it causes positive feelings in the child. It's most difficult to remove it.

A child's behavior can perform different functions, for example, in one case, the child hits their head because they wants to get the parent's attention, in another thet wants to escape a requirement or to get a favorite drink at lunch. If we want to find out what is the behavior, we have to perform a functional analysis.

\section{Functional analysis}

In literature, we often encounter the term the $\mathrm{ABC}$ model. The $\mathrm{ABC}$ model of functional behavior analysis reveals the cause of problem behavior, self-stimulation, aggression, auto-aggression, destructive behavior or other forms of behavior. What is important is that it precisely defines behavior but also the effect. The ABC model is derived from the English words Antecendent, Behavior, Consequence (Cosgrave, 2015). The antecendent or even the cause is all that happened before the behavior. It's a behavior trigger. It can be in a variety of forms and can also cause desired and problematic behavior. It takes place just before the behavior begins (Cooper et al., 2007). Behavior, therefore, includes a very detailed description of the behavior, its duration, intensity, and the whole course of behavior from start to finish. Consequence is all that happened just after the end of the behavior. The revelation of the consequences can explain why the behavior observed in the future was repeated (Organ et al., 2006).

In addition to problem behavior, the $\mathrm{ABC}$ model is also used for learning. In that case, A represents the $\mathrm{Sd}$, the stimulus we give to the child. $\mathrm{B}$, the child's response and $\mathrm{C}$, is a boost or correction of the answer. 
We can use such an analysis if learning is not successful to uncover the cause of the child's failure. Example:
A: Say: "Car"
B: Child says: "Car"
C: I give him/her a car, or I admire.

Data collection and the $\mathrm{ABC}$ analysis will help identify what behavior is triggering, as well as what strengthens it and why it is repeated. This enables us to develop a plan for positive behavioral change (Richman, 2006). For recording we can use various forms and record sheets, which in addition to antecendents, behavior and consequences also contain other quantities such as date, time, and duration.

\section{Research}

We have decided to point out the effectiveness of ABA's curriculum developed for individuals with autism spectrum disorders, with who we have worked individually and also to describe some ABA strategies that could be used by individual assistants with disabilities in kindergartens.

The main aim of the research is to qualitatively point out how to work with a child with autism through applied behavioral analysis based on a behavioral plan developed by a certified BCBA therapist Mgr. Ivana Trellová.

It is also part of the research to show B.F.Skinner's process of developing an autistic spectrum disorder individual for quantitative changes that occurred due to ABA intervention.

Another goal of the empirical part is to highlight the use of applied behavioral analysis in a kindergarten environment through a case study.

To implement our research, we have decided to use qualitative research tools, using the following methods: participatory observation, interviewing, ABA methods, analysis and evaluation of collected data.

The research sample with regard to qualitative research consists of three participants. Two, with whom we have worked with for a long time under the supervision of Mgr. Ivana Trellová BCBA and one participant with whom the research was conducted in kindergarten. Given the range of the results, we present the results of the participant with autism.

For ethical reasons and protection of personal data, the name of our respondent was not published and therefore we will address him as "Student". The child's age at the beginning of the cooperation was three years old, male gender, and the main diagnosis is autism. The Student was from the first pregnancy of the mother, who had no complications; all the results were normal in the prenatal, perinatal and postnatal period. The birth was imperial, the baby cried after birth and had adequate birth weight and height. The baby had no neonatal jaundice and was breastfed for half a year. According to her mother, developing was according to the tables until approximately a year and a half. He was very nice, he started to walk, before he reached the first year, and he could say a few basic words ("mom", "baba"). He showed things in the books and was interested in the surroundings. Around 18 months of his age, a regression of acquired skills began. The child lost eye contact, stopped using the learned words and sounds, didn't care about the surroundings. His behavior was characterized by greater shouting or pushing away, if he doesn't like something. He likes car driving, well-known activities, jigsaw puzzles, songs, he likes to watch videos. He does not like dressing, the cutting of his hair or nails, washing hair or soups. There is problem behavior when presenting these activities. He has no other diagnosis other than intolerance to egg whites. He uses nutritional supplements and common vitamins. He is currently attending a special kindergarten for pupils with autism. The boy, whose work began with a consultation program and continued with an intensive two-month program, included developing the following areas in the ABA Educational Plan:

- Mandas - a student asks for 10 different activities or things.

- Imitation with objects.

- Motor imitation.

- Visual discrimination.

- Receptive understanding.

- Cooperation. 
After the first meeting, where we were more observers and watching what games the child chooses and what he is interested in, a pairing period followed. Pairing is a term used in ABA to name the process of building a relationship between a therapist and a child. During pairing, we offered the child more rewards than requirements, trying to create situations that were fun for the child. The result of pairing is that the child wants to be more with the therapist than without him. The length of pairing varies; according to some authors it is appropriate to spend at least 2 weeks at the beginning of the intervention and also some time $(5,10$ minutes) at the beginning and end of each intervention. Our work with the participant was quite good at the beginning; we recorded the number of arrival and escape of the child by a mechanical counter. When we saw that the number of arrivals was rising, we began to add more and more simple requirements to the game. During each meeting, we had various sub-goals that we worked on using ABA methods and techniques.

At the beginning of our meetings, the boy showed very weak eye contact. During our work, we tried to make eye contact improvements in our playful activities. We created a situation where the child's motivation was high, and then we stopped the game and only continued after the child looked at us. They were various activities like singing, dancing, tickling. If the child did not initiate eye contact within a few seconds, we searched for it and continued the fun activity.

In addition to pairing between us and the students, we also tried to pair the table so that after we start working on academic skills behind the table through DTT learning, the table for our student did not become an adverse stimulus and there was no problem behavior.

One of the important programs we initially trained with the student was following the subject. This program has been divided into three steps:

- The child follows an object moving from one side to or from bottom to top.

- The child follows the subject we move in any way.

This goal was managed by the student, if he did it for four consecutive days. It took a few days for the student to concentrate on the moving subject. After managing the goal, we tested step two, which he immediately managed, which means that he had a $100 \%$ success rate from the three tests. On this day, too, the third step of this skill was introduced, which was more was challenging for the student, as he had to follow the subject for seven seconds, and learning this step took the longest time. During this program, we also worked with students on other behavioral and academic skills. For family reasons, the student's consultation program was interrupted in May and June and we started an intensive program from July 2017.

In the month of March and April, when the student's demands were raised and we started to work more on academic skills, the student was faced with problem behavior. The most common feature of problem behavior was to escape the requirement. Almost the entire period of the intensive program, we watched and recorded the follow-up of simple requirements, after which the student's behavior was strengthened. This proactive strategy has led to a reduction in problem behavior because the desired behavior has been strengthened.

\section{Motor Imitation}

The ability of imitation is a basic function in children, through which they learn different skills modeled by parents, teachers or siblings. This ability is disrupted in some individuals. Imitation is largely absent from individuals with autism spectrum disorders, and so it was one of the first programs taught to our student. During the consultation program, we trained with the student to imitate some movements of gross motor skills that the student had managed. After a two-month break, we had to test and also learn these skills again. The ability to imitate during our intensive work with our student significantly improved, especially in the area of gross motoring, which we achieved through the application of the principle of empowerment and prompting.

Our student is currently using gestures to express his needs, while learning the ability to imitate them is very important. In addition to the movements of gross motor skills, we also included imitation of fine motor skills into the programs. Imitating the movements of the fine motor skills of the hand was very challenging for the student, and the student did not differentiate the modeled movements and often imitated the previously learned movements. During the testing, the student showed that he did not impede any movements of the oromotor and facial motor skills (tongue twitching, squinting, and blowing). During the game in the natural environment we also tried vocal imitation and after finishing 
the program the student was able to imitate simple syllables like "pi" and "ham". In addition to imitation, the syllable "pi" was also functionally used as a mand for water

\section{Mandas}

The area that is most disrupted in individuals with autism spectrum disordes and is not developing adequately with the child's age is the area of communication. With our student, together with his parents, we decided to learn sign-based communication, as our student did not speak or imitate any words. At the beginning of an intense program, the student knows some signs, but he did not use them functionally. Mostly he just imitated the signs, confused them, or used multiple gestures at once to reach the desired subject. During the intervention, we recorded mechanically the teachings of mandas requirements. While learning Mandas, we taught the student mandy for which he was motivated and of great value to him. Manda Criterion: Mand is mastered if a student uses it for 5 consecutive days. During the intervention, we provided various types of prompts from full prompt through partial, until the student used the sign alone or after asking "What are you asking?" - without help.

When teaching mandu twirl, advancement of $48 \%$ with a separate mand occurred after 4 consecutive days. The student still required help in making a twirl and it took a few more days for the student to meet the mandate criterion for mastering the mand twirl.

Another mand was jumping. While learning this mand, we saw the student with the greatest motivation and the first day after the introduction of the mand, the student asked for it without the use of a prompt. On the fourth day, the student had a nearly $60 \%$ success in requesting the activity.

One of the taught mand was also mand to request cheese. We have always cut the cheese into tiny pieces so that we have as many learning opportunities as possible. Although the student liked cheese very much and the motivation was high, not every day he was interested in cheese.

At the beginning of an intensive program, we emphasized the creation of a repertoire of interests and possibilities for learning mands.

When learning mand - sign, the student was demotivated if he could not imitate the movement of fine motor skills. We assumed that the signs must be different because the student does not see the difference in them and uses one universal sign.

When using the prompts for new signs, it was better to use the full prompt for a longer period of time, if a partial prompt was used quickly, the student created his own sign or already learned it.

If the sign was too heavy, the student lost interest in the subject or activity.

From our observations, we found that the student began to notice the motions of fine motor skills while imitating mands and to imitate them. We have also seen that the student was more interested in using signatures as one of the means of communication. At the end of the intensive program, the student functionally used 10 mands to request these things or activities: cake, turn on, open, candy, swing, blow, jump, spin, ball, and drink.

\section{Receptive understanding}

The receptive component of language is a very important prerequisite for successful communication of individuals. With our student, this area is severely disrupted, so the inclusion of receptive understanding has been an important part of the ABA plan. In the area of receptive understanding, we have initially tested the understanding of contextual situations. The student understood and then made simple instructions that resulted from the situation, such as opening a door when leaving the room, give me a toy car in a common game, sit here, stand up and similar simple instructions. ABA 's curriculum in receptive understanding focused on:

- Recipe instruction. In the area of receptive understanding, the instructions related to the movement of gross motor skills, which the student had already mastered in the field of motor imitation, such as: clapping, making an Indian, putting hands up, scratching tummy.

- Receptive identification of body parts. In the area of receptive identification parts of the body, it took a longer time for the student to learn the skills. In this program, the influencing factor was our prompt, which was a model at the start of learning. Later we realized that the student did not respond to the heard instruction, but at our prompt and therefore the movement only imitates no receptive identification. After we changed the prompt from the model to physical, and after entering the movement instruction made with the student's hand, the learning 
progressed faster. At the end of our program, the student was able to identify his head, abdomen, nose, leg on his body and also learned new target skills, among which were his eyes and knee. After managing the identification parts of his body, the next step was to generalize this skill to other people.

- Receptive identification of objects. In the area of subject identification, we started to identify items in field one that the student had already mastered during testing. Identifying objects in the field of three was a new program for our student that was more challenging for him. On the last day he could only identify one subject in this program, and for the next two he had not yet mastered the required criteria.

The criterion for managing this program was the correct response for four consecutive days. We developed the target skills of these areas during intensive learning behind the table as well as learning in the child's natural environment.

\section{Conclusion}

In an individual with autism, there was a visible progression for eye contact, which was significantly disrupted at the beginning of the intervention. He also improved his name response, which we and his parents stopped using when giving instructions, so that the student was not associated with work or any unpleasant requirement.

During the consultation program, the student often encountered problematic behavior that was due to crying, shouting, or throwing things onto the ground. The problematic behavior occurred mainly in the transition from popular activity to other activity.

Through the principle of empowerment, the student's behavior was greatly reduced and obedience improved after the request was made.

During the months of July and August, we mechanically recorded the follow-up request, and the data collected showed us that the student met all the requirements on average $80 \%$ during the two-hour session at the end of the intervention. Given the individual's diagnosis, this is a very positive advancement. The category of simple requirements also included moving from activity to activity linked to the instruction: "Come with me", which the student began to accept without any problematic behavior that was reduced by applying the principle of extinction.

A change in an individual's behavior also occurred when working behind a table, where there was a problematic behavior with a function of escape. During the intervention, a timer was introduced in which the student had a set time of three minutes at the beginning of the intervention. The student learned through the timer to work at the table without any problem behavior and stopped arbitrarily leaving the table after the signal and the instruction "done, you can go" he left. During this procedure, the student greatly initiated eye contact when leaving the table. The time was gradually extended and reached eight minutes after two weeks of training. We consider the duration of work behind the table as very positive, as it is an individual with serious autism spectrum manifestations.

Student did not use words or gestures to communicate at the beginning of the intervention to reach the desired item. If he wanted something, he took the hand of the parent, or the therapist, and led them to the desired item. Sometimes he used crying or screaming to achieve his needs. During the consultation program, the student began to learn gestures to request a favorite activity (turn on, open) or favorite snacks (candy). During the consultation program, the student did not control the imitation of many movements of fine motor skills, which had a significant impact on the mand learning by means of gestures. Signs were stranded and could not be used alone.

During an intensive program, a repertoire of interests was created for the student during a two-month period of work, and the process of learning mands could be streamlined. From the results we can say that the student's communication through the mands improved and on the last day of the intervention he independently controlled 10 signs.

After the first meeting, Student could be described as having a low interest in the environment. The precursor to receptive understanding was the three-step learning of the subject. In the first step, the student had to follow the subject only for two seconds in the direction from top to bottom or right to left. Managing the first step took five days. All skill, that is, all three steps, the student had managed for one 
month, but the skill was constantly repeated and strengthened through game activities and learning in the natural environment. The student has improved significantly in this program.

Imitation has a great influence on the development of social as well as communication skills, which develops in intact children by natural maturation. Our student had the ability to imitate undeveloped. During the intervention, we focused on imitating the movements of gross motor skills and gradually moving towards more complicated movements of fine motor skills. As a positive result, until the end of the intervention, the student learned to imitate sixteen movements of gross motor skills, which were particularly challenging for him at the beginning of the intervention. We attribute this success to the implementation of prompting and intense empowerment.

\section{References}

Aue-Vandenberd, M. (2017). Special Learning. [Web blog post]. Retrieved from https://www.speciallearning.com/blog/article/112

Cooper, J.O. et.al. (2007). Applied behavior analysis. New Jersey : Pearson.

Cosgrave, G. (2015). Functional Behaviour Assesment. Retrieved from http://www.educateautism.com/functional-behaviourassessment.html

Gilmore, H. (2015). How to Change Human Behavior: Basic Concepts in ABA (Applied Behavior Analysis). Retrieved from https://pro.psychcentral.com/child-therapist/2015/05/how-to-change-human-behavior-basic-concepts-in-aba-appliedbehavior-analysis/

McCleland, A. (2016). Comparison of pivotal response treatment (PRT) and Discrete trial traing (DTT). Retrieved from https://pdfs.semanticscholar.org/dfea/25edb3457e3a31d67750917ae69948afb6b4.pdf

Organ, D.W. (2006). Organizational Citizenschip Behaviour. California: Library of Congres cataloging in publication data.

Simplesteps

SIMPLESTEPS. (2017). Vzdelávací program, který vás provede prvními krokmi na ceste k tomu jak se stát rodičemterapeutem. Brno: Tisk tiskárna Helbich.

Zeisig, E. (2012). Function of Behavior: Everybody E.A.T.S. Retrieved from https://barefootbehavior.wordpress.com/2012/01/16/functions-of-behavior-everybody-eats 